Dr. Simpson's method," (i.e. separate the whole placenta), and when the patient rallies attempt version. Should there be transverse presentation, rectify it by Dr. Hicks' combined method of version, and if this does not succeed use internal version.

\title{
Review V.
}

Report of the Sanitary Commission for Bombay, 1864. 8vo, pp. 285. Bombay, 1865.

IT is much to be regretted that the several reports of the sanitary commissions at the different presidencies of India have not, as far as we know, been made generally public in this country. The only one that has reached us is the first issued by the Bombay commission; and as this does not contain copies of the correspondence between Dr. Leith, the president, and the War Office on various topics about sanitary matters referred to, the information given is not so complete as might have ween reasonably looked for. Whether the unwillingness to pring before the public eye all the printed official documents relating to the different commissions be on the part of the authorities of home or of those in India, it is to be hoped that all reticence will henceforth cease, and that the several publications issued by these boards shall be made freely and at once accessible to all who are interested in the results of their proceedings.

The unnecessarily high death-rate of 69 per 1000, assumed by the Royal Commission for the British Army in India generally, excited no small amount of criticism among the medical officers of the service there as well as in this country. In the Bombay presidency more especially, in which the mortality among the troops was always much less than in most other parts of the peninsula, strong exception was taken to the standard adopted by the commissioners; nor could this be wondered at when it appeared that not only had the death-rate in the last fifteen years never reached one half the above estimate, but also that, during this period, there had been a very marked and progressive diminution going on in the annual amount of sickness and death throughout the Bombay army. It would seem that the comments made on this subject by the sanitary commission of this presidency had caused the issuing of some counter-remarks by the Barrack and Hospital Improvement Commission of the War Office; for the report now before us contains a reply to 
these remarks on other points besides that of the annual deathrate, which had given rise to difference of opinion, such as the sort of latrine best suited for barracks in India, the readiest and least noxious means of disposing of latrine and other sewage of cantonments in India, the arrangements for the water supply, \&c. Plans and methods which are indubitably the very best in this country will often be found to be scarcely applicable, at least without considerable modification of details, in regions so very dissimilar in their condition as a British county must be from a district of Hindostan; and the Royal Commissioners seem to have sometimes overlooked this consideration.

Although the statistics for one year only of the relative sickness and death among. British and native troops afford slender grounds for comparison, the subject is so important for future reference, that the following data may be worth recording. In the medical year of fifty-three weeks, from 26 th December, 1863, to 30th December, 1864, the mean strength of the British troops in the Bombay presidency was 12,412 . The admissions into hospital were at the rate of 1514 per thousand of the force; and, on an average, there were 59 per thousand always in hospital. The death-rate from all causes, both in and out of hospital, was 15.87 per thousand. Besides this decrement, 169 , or 13.6 in every 1000 men, were invalided for discharge; so that the total loss to the service, in the course of the year, was at the rate of $29 \cdot 4$ per 1000 of the entire force.

Fevers and hepatic disease were the chief causes of death; 28 per cent. of the whole mortality was due to them. Cholera (which proved fatal in rather more than in half the attacks) stood next; it occasioned 10 per cent. of the deaths; and about the same proportion was attributable to diarrhœa and dysentery. Of the total 197 deaths, 23 were from violence; 6 of these were from suicide.

The native force serving at stations in Bombay averaged 22,501. The hospital admissions were at the rate of 975 , and the deaths at the rate of $14 \cdot 30$, per thousand. Particulars are not given as to the principal causes of either the sickness or the mortality. All that is stated is that cholera occasioned considerably more than a third of the whole deaths, the ratio from this disease alone being 5.91 per 1000 of the entire force. The want of details respecting the health-state of the native troops in India is a great desideratum, which it is earnestly to be hoped will ere long be supplied. The materials are in existence, and it requires but an order of the Secretary of State for India to have them utilised for the good alike of the service and of statistical science. Besides the above force at Indian stations, there were 1425 native soldiers on foreign service in China, and 989 were 
stationed at Aden. The death-rate in China was very high, being $29 \cdot 47$ per thousand-4.21 from cholera alone. At Aden, although there was no cholera, the ratio of mortality was, nevertheless, $25 \cdot 71$; " due in great measure to the scorbutic diathesis that troops acquire at that station." If such be the explanation of this extremely high death-rate, the remedy is of course obvious by the regular issue of lemon-juice and fresh vegetables to the troops.

At the present time, when the subject of the prophylaxis of cholera is attracting so much attention, the following recommendations, as to the measures that should be enforced in respect of what is called the "pilgrim nuisance" during an epidemic season, are worthy of note:

"It might be ruled that pilgrims returning from a pilgrimage at which cholera has appeared, shall not enter any cantonment or town until after reasonable evidence that that they are free from infection;the evidence required being that they are free from diarrhoea or other signs of the disease, and that two whole days have elapsed since they were in personal communication with, or in the society of, a person ill with cholera or diarrhœa. Should there not be indisputable evidence of this, the pilgrims should be kept under observation for forty-eight hours; and after that time, if no symptoms of the disease be manifested among them, they might be allowed to pass. Should, however, any of the party show signs of cholera, they should be separated at once from the rest, and these others should begin anew a two days' period of probation. . . . There should be separate accommodation for the sick. If proper tents be not readily procurable, native blankets joined together and stretched over bamboos or other poles would do."

Suitable latrines should of course be provided for the detenus, and arrangements made that earth be thrown in on the excreta by every person making use of them. The discharges from the sick should also be disinfected with lime, chloride of zinc, or some other similar corrective.

The only other topic to which we can now briefly allude is the important and, it must be confessed, somewhat difficult question "as to the period during which troopships with smallpox cases on board should be detained in harbour before putting to sea." The subject was referred by the Bombay board to the Barrack and Hospital Improvement Commission for its opinion, to guide them as to what should be done in such cases in future. The Commissioners seem to avoid committing themselves to any. definite recommendation on the point in question, as will appear from the following passage in their reply :

"After actual cases of smallpox or other epidemic diseases have been removed out of the ship, after incipient cases of the disease have 
been disposed of, after every necessary hygienic measure has been carried out, and the health of those on board has been ascertained to be satisfactory, then the question as the period of detention of the vessel has to be decided. If there is no reason to apprehend a renewal of attack, the vessel may proceed on her voyage. If it is considered advisable to detain her for a day or two, it should be

The caution of this reply will probably have somewhat disappointed the wishes of the board; they will not feel much strengthened by the advice.

\section{Review VI.}

1. Die Inhalations-Therapie in Krankheiten der RespirationsOrgane, mit besonderer Berïcksichtigung der durch Laryngoscop ermittelten Krankheiten des Kehlkopfs. Von Dr. Georg LEwin. Mit 25 Holzschnitten Zweite Auflage. Berlin. 1865. Pp. 506; mit Anhang, pp. 37.

The Treatment by Inhalation of Diseases of the Respiratory Organs, with especial reference to the Diseases of the Larynx as revealed by the Laryngoscope. By Dr. G. Lewin.

2. On Inhalation as a means of Local Treatment of the Organs of Respiration by Atomized Fluids and Gases. By Hermans Beiget, M.D., \&c. With Woodcuts. London. 1866. Pp. 200.

3. On the Treatment of Affections of the Throat and Lungs by Inhalation, \&c. By W. Аввоттs Sмiтh, M.D., \&c. Second Edition. Liondon. Pp. 48.

4. Inhalation, the most rational treatment for Diseases of the Respiratory Organs. By C. F. Sснмid, M.D., and C. Milner. M.D. London. 1865. Pp. 35.

PUBLIC attention has been called to the subject of the inhalation of medicated vapours, by a recent trial of considerable interest to the profession. So far as the opinions expressed by the able physicians engaged on the side of the defendant may be allowed to represent the views entertained by the profession at large respecting the usefulness of such inhalations in chest disease, they may be cited in argument against the existence of such utility. On the other hand, much value was assigned to them on the plaintiff's side, almost wholly, however, on a bare assertion. At the same time the inference was fairly deducible, that little attention and slight experimental research have hitherto been 